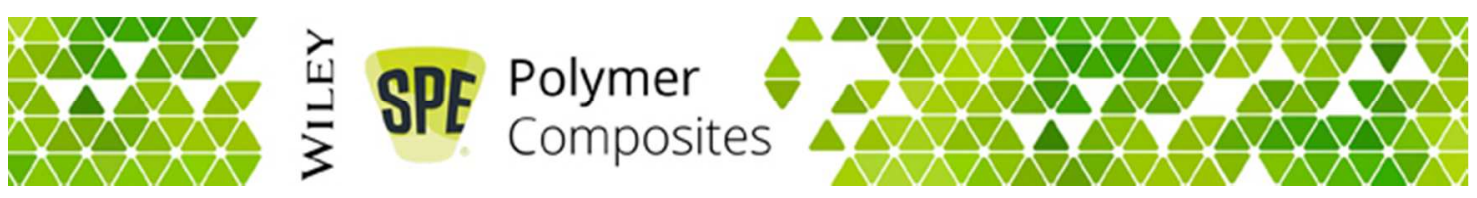

\title{
Production and characterization of bamboo and flax fiber reinforced polylactic acid filaments for fused deposition modelling (FDM).
}

\begin{tabular}{|c|c|}
\hline Journal: & Polymer Composites \\
\hline Manuscript ID & PC-18-0317 \\
\hline Wiley - Manuscript type: & Research Article \\
\hline Date Submitted by the Author: & 14-Feb-2018 \\
\hline Complete List of Authors: & $\begin{array}{l}\text { Depuydt, Delphine; KU Leuven, Department of Materials Engineering, } \\
\text { Group T Leuven Campus, Andreas Vesaliusstraat } 13 \\
\text { Balthazar, Michiel; KU Leuven, Department of Materials Engineering, Group } \\
\text { T Leuven Campus, Andreas Vesaliusstraat } 13 \\
\text { Hendrickx, Kevin; KU Leuven, Department of Materials Engineering, De } \\
\text { Nayer Campus, Jan De Nayerlaan } 5 \\
\text { Six, Wim; KU Leuven, Department of Materials Engineering, Bruges } \\
\text { Campus, Spoorwegstraat } 12 \\
\text { Ferraris, Eleonora; KU Leuven, Department of Mechanical Engineering, De } \\
\text { Nayer Campus, Jan De Nayerlaan } 5 \\
\text { Desplentere, Frederik; KU Leuven, Department of Materials Engineering, } \\
\text { Bruges Campus, Spoorwegstraat } 12 \\
\text { Ivens, Jan; KU Leuven, Department of Materials Engineering, De Nayer } \\
\text { Campus, Jan De Nayerlaan } 5 \\
\text { van Vuure, Aart; KU Leuven, Department of Materials Engineering, Group T } \\
\text { Leuven Campus, Andreas Vesaliusstraat } 13\end{array}$ \\
\hline Keywords: & biopolymers, processing, mechanical properties, compounding, biofibers \\
\hline
\end{tabular}

\section{SCHOLARONE}

Manuscripts 
Production and characterization of bamboo and flax fiber reinforced polylactic acid filaments for fused deposition modelling (FDM).

Delphine Depuydt ${ }^{\mathrm{a}}$, Michiel Balthazar ${ }^{\mathrm{a}}$, Kevin Hendrickx ${ }^{\mathrm{b}}$, Wim Six ${ }^{\mathrm{c}}$, Eleonora Ferraris ${ }^{\mathrm{d}}$, Frederik Desplentere $^{\mathrm{c}}$, Jan Ivens ${ }^{\mathbf{b}}$, Aart W. Van Vuure ${ }^{\mathrm{a}}$

${ }^{a}$ KU Leuven, Department of Materials Engineering, Group T Leuven Campus, Andreas Vesaliusstraat 13, 3000 Leuven

${ }^{\mathbf{b}} \mathrm{KU}$ Leuven, Department of Materials Engineering, De Nayer Campus, Jan De Nayerlaan 5, 2860 SintKatelijne-Waver, Belgium

${ }^{\circ}$ KU Leuven, Department of Materials Engineering, Bruges Campus, Spoorwegstraat 12, 8200 Bruges, Belgium ${ }^{\mathrm{d}}$ KU Leuven, Department of Mechanical Engineering, De Nayer Campus, Jan De Nayerlaan 5, 2860 SintKatelijne-Waver, Belgium

\footnotetext{
${ }^{1}$ Corresponding author: Delphine.Depuydt@kuleuven.be
} 
Production and characterization of bamboo and flax fiber reinforced polylactic acid filaments for fused deposition modelling (FDM).

Delphine Depuydt ${ }^{\mathrm{a} 2}$, Michiel Balthazar ${ }^{\mathrm{a}}$, Kevin Hendrickx ${ }^{\mathrm{b}}$, Wim Six ${ }^{\mathrm{c}}$, Eleonora Ferraris ${ }^{\mathrm{d}}$, Frederik Desplentere $^{\mathrm{c}}$, Jan Ivens ${ }^{\mathrm{b}}$, Aart W. Van Vuure ${ }^{\mathrm{a}}$

${ }^{a}$ KU Leuven, Department of Materials Engineering, Group T Leuven Campus, Andreas Vesaliusstraat 13, 3000 Leuven

${ }^{\mathbf{b}} \mathrm{KU}$ Leuven, Department of Materials Engineering, De Nayer Campus, Jan De Nayerlaan 5, 2860 SintKatelijne-Waver, Belgium

${ }^{c}$ KU Leuven, Department of Materials Engineering, Bruges Campus, Spoorwegstraat 12, 8200 Bruges, Belgium ${ }^{\mathrm{d}} \mathrm{KU}$ Leuven, Department of Mechanical Engineering, De Nayer Campus, Jan De Nayerlaan 5, 2860 SintKatelijne-Waver, Belgium

\begin{abstract}
A new type of fiber reinforced filament materials for Fused Deposition Modeling (FDM) applications has been developed. Polylactic acid (PLA), compounded with two types of plasticizer, is reinforced with bamboo and flax fibers. The fiber fractions are characterized by measuring their length (1) over diameter (d) before and after compounding so that the effect of the $1 / \mathrm{d}$ on the final filament properties can be systematically studied. The preprocessing and processing activities, to produce filaments with a diameter of $3 \mathrm{~mm}$, are described. The porosities and the orientation of the fibers in the filament are assessed in order to predict the theoretical stiffness of the filament via short fiber mechanics which is compared to the experimental results. Reinforcing the PLA filament with short bamboo fibers $(1 / \mathrm{d}=4.1-4.7)$ increases the modulus with $91-230 \%$, whereas the dust-like fractions only show an increase up till 39\%. An interfacial study is performed to study the effect of the plasticizer on the adhesion. Furthermore the glass transition temperature of the produced filaments is determined to investigate the suitability of the filaments and finally a demonstrator part was printed.
\end{abstract}

\footnotetext{
${ }^{2}$ Corresponding author: Delphine.Depuydt@kuleuven.be
} 


\section{Introduction}

Fused deposition modelling (FDM) is the most widely adopted additive manufacturing technique [1]. Similar as to other additive manufacturing techniques the part is built layer by layer, but characteristic to FDM is the continuous extrusion and deposition of material heated above its melt temperature. When a polymer filament is used as feedstock, the filament acts as a piston pushing the molten material through the liquefier [1, 2]. Among the benefits of FDM belongs the possibility to create complex parts with no need of specific tooling and a reduction of waste due to the fact that materials are added instead of subtracted $[1,3]$. Furthermore the lead times are short, making it a cost effective method for small batches [3]. The limits nowadays are the narrow range of available materials, bad surface finish and limited mechanical performance $[1,3]$.

Several authors have tried to optimize the printing process by investigating for example the influence of the building orientation, fill percentage, layer width and stacking sequence [4-6]. These adjustments can improve the strength of the printed part but will not allow exceeding the strength of the pure polymer. Spoerk et al. [6] found that $80-90 \%$ of the tensile strength of compression molded PLA could be achieved by optimizing the printing parameters of PLA. FDM was originally targeting prototyping applications; now a shift is seen to enduse parts [2] for which higher requirements are set, raising the need for more fundamental research on new materials and new techniques [1,7]. In this context, filaments were reinforced with metallic, ceramic and fibrous fillers.

Masood et al. [8] investigated adding coarse $(50-80 \mu \mathrm{m})$ and fine $(<30 \mu \mathrm{m})$ iron particles to a nylon matrix with plasticizer. The filament was tested and it was observed that the tensile modulus increased by $14 \%$ when large particles were used, while the strain to failure for the filament reinforced with fine particles was almost 6 times higher. Ning et al. [9] added carbon fiber powder to ABS pellets. The carbon fibers had an average length of $150 \mu \mathrm{m}$ and a fiber diameter of 7.2 $\mu \mathrm{m}$. Results showed that the largest Young's modulus $(E)$ could be achieved with $7.5 \mathrm{wt} \%$ carbon fibers, $E=2.5 \mathrm{GPa}$, with the stiffness of the pure polymer being $1.9 \mathrm{GPa}$ only. The largest tensile strength was measured at $5 \mathrm{wt} \%$ carbon fiber being $42 \mathrm{MPa}$, compared to the pure ABS which has a strength of $34 \mathrm{MPa}$. From the experiments in literature it becomes clear that the type of reinforcement, the shape and the volume percentage will have an influence on the eventual properties of the filament and printed part. 
Beside the traditional materials also more green materials are being implemented in FDM applications. A growing awareness of the depletion of our resources changes the mind-set of researchers worldwide [3, 10, 11]. Several attempts already refer to the production of FDM filaments with natural fibers. Safka et al. [12] compounded milled coconut fibers $(2-5 \mathrm{~mm})$ in an ABS matrix and created 3D printed tensile bars. The measured modulus for a 3D printed tensile bar with $15 \%$ coconut fibers was $1.96 \mathrm{GPa}$ with a strength $(\sigma)$ of 21.4 MPa and a strain to failure $(\varepsilon)$ of $2.8 \%$. Compared to the injection molded ABS $(E=1.88 \mathrm{GPa}, \sigma=29.6$ $\mathrm{MPa}, \varepsilon=8.5 \%$ ) a slight increase in stiffness was found and a decrease in strength and strain to failure. An opposite trend is seen when the same coconut fiber reinforced pellets are injection molded. Then an increase in strength of $43 \%$ and a doubling of the stiffness is found with an elongation to failure similar to the $3 \mathrm{D}$ printed part. These improved properties compared to the 3D printed counterpart, are explained by a better homogenization in the injection molding process, leading to better cohesion of the fibers and the surrounding matrix. Kariz et al. [13] compounded wood particles into a PLA matrix and saw an increase in filament modulus from 3.27 GPa for pure PLA to $3.94 \mathrm{GPa}$ with the addition of $20 \%$ of wood. Higher wood levels did not increase the properties since the polymer could not fully encapsulate the particles with as result poor bonding and limited load transfer.

In literature divergent effects are seen regarding the mechanical properties of filler reinforced filaments. Therefore, in this research a systematic approach is adopted to study the influence of flax and bamboo fiber length and diameter on the produced PLA filament. The fiber fractions are characterized before and after compounding, so that deeper insight is gained in the compounding process. Tensile tests are performed on the produced filament and the experimental results are verified with the theory on short fiber mechanics [14, 15], from which it is known that the higher the length over diameter $(1 / \mathrm{d})$ ratio of the fibers, the stiffer the composite. In this calculation the orientation of the fibers and the amount of porosities present in the part is also accounted for [16]. Two types of plasticizer were selected to be added to the filament and an interfacial and thermal study is performed to assess their applicability.

\section{Materials and Methods}

\section{$2.1 \quad$ Materials}

Virgin PLA was compounded with plasticizer and reinforcing fibers. Plasticizer was added to lower the brittleness of PLA [17] and guarantee the winding of the filament. Furthermore it has been suggested to improve the surface finish, layer adhesion and decrease the pore size [18]. The PLA pellets were compounded 
with two types of plasticizers, both provided by Proviron Industries NV (Belgium), referred to as cPLA1 and cPLA2. Two types of natural fibers, bamboo and flax, were chosen as reinforcement. Four distinguishable bamboo fiber fractions with lengths between 0.1 and $4 \mathrm{~mm}$ were investigated. Fraction 1 was sieved out of dry sawdust of the company Buco Import BVBA (Belgium). A first sieve step was performed using a sieve with mesh size $630 \mu \mathrm{m}$, followed by a sieving step with a $315 \mu \mathrm{m}$ mesh size. The remaining fraction (in between 315-630 $\mu \mathrm{m})$ is referred to as fraction B1. Fractions B2-B4 were provided by the company Bambooder Biobased Fibers B.V. (Netherlands). Flaxtape, supplied by Lineo NV (Belgium) was cut into two different lengths of $2 \mathrm{~mm}$ (F1) and $5 \mathrm{~mm}$ (F2) prior to compounding. A commercially available PLA filament filled with $20 \%$ bamboo particles named Bamboofill, produced by Colorfabb (Netherlands), was used as a reference.

\subsection{Preparation and manufacturing of the filament}

All the fiber fractions were pre-dried for 7 hours in a Moretto D4T hot air dryer at $90^{\circ} \mathrm{C}$ to a humidity of maximum 400 ppm, except for three fractions that were due to logistic reasons dried in a vacuum oven for the same amount of time. The pellets of PLA were dried after production, hermetically sealed and opened just before processing. The plasticizer was added in a liquid form. The compounds were made with a Leistritz ZSE 18 MAXX 36D twin extruder with a screw diameter of $18.5 \mathrm{~mm}$ and a screw length of $36 \times \mathrm{D}=666 \mathrm{~mm}$. The temperature settings and screw profile are shown in Figure 1.

Temperature was ranging from $165-200^{\circ} \mathrm{C}$ in the different zones, and the material was fed at specific screw sections and temperatures. Specifically, the PLA granules were fed to the screw first at $200^{\circ} \mathrm{C}$, later the plasticizer was added at $185^{\circ} \mathrm{C}$ and, further down the line, the fibers were added via the side feeder at $175^{\circ} \mathrm{C}$. A vacuum pump was installed in the metering section to remove the moisture that was desorbed from the fibers or PLA during the processing. The extruder speeds used were $200 \mathrm{rpm}$ and $350 \mathrm{rpm}$. Filaments were compounded with $15 \mathrm{wt} \%$ fibers, $10.2 \mathrm{wt} \%$ plasticizer and $74.8 \mathrm{wt} \%$ PLA. After exceeding the die the filament was given the time to slowly cool down before winding, in order to avoid the creation of voids.

Bamboo fibers were added directly to the extruder via an external feeder, with a weight based dosage. Flax fibers needed an impregnation step before compounding to obtain a homogeneous fiber distribution. The fibers were first mixed with compounded PLA pellets (including plasticizer) and pressed into plates of 30 by $30 \mathrm{~cm}$ and $0.4 \mathrm{~cm}$ thickness. These plates were then cut into smaller pieces of $4 \mathrm{~mm} \mathrm{x} 4 \mathrm{~mm} \times 4 \mathrm{~mm}$ which were fed to the extruder in order to produce the flax filament. 


\subsection{Determination of the length to diameter ratio}

The length and diameter of the fiber fractions were measured using two image processing algorithms. The algorithm for the diameter determination is explained by Hendrickx et al. (2015) [19] and starts from a flatbed scanned image at 1200 dpi. After putting a threshold to separate the fibers from the background and morphological operations to clean the image, the fiber diameter is determined by taking the local maxima of the Euclidean distance transform function. A second algorithm was used to determine the fiber length, this algorithm starts from the same scanned image of the fibers, where a threshold is applied and fibers crossing the image border are removed. A skeleton of the fibers is determined and the end effects and crossing fibers are removed. The fiber length is determined as the Euclidean distance between the two fiber ends. The fiber length is calculated and displayed on top of the original image for control purposes [20-22]. For each analysis at least 200 fibers were measured.

The distribution of the fibers is displayed in a boxplot, where Figure 2 shows the explanation of the different symbols. Measurements were identified as outliers when they were greater than $\mathrm{q} 3+\mathrm{w} \times(\mathrm{q} 3-\mathrm{q} 1)$ or less than $\mathrm{q} 1-\mathrm{w} \times(\mathrm{q} 3-\mathrm{q} 1) . \mathrm{q} 1$ and $\mathrm{q} 3$ are the 25 th and 75 th percentiles of the sample data, respectively. With the default value of $\mathrm{w}$ being 1.5 , this corresponds to approximately $\pm 2.7 \sigma$ or 99.3 percent coverage if the data are normally distributed. The whiskers in Figure 2 extend to the most extreme value that is not an outlier.

Fiber length and diameter determination after compounding was executed by first dissolving the PLA of the filament in dichloromethane (DCM, 99.8+\% purity, amylene stabilized). Around 1.5 gram of the filament was weighed and submersed in DCM while stirring. After 1 hour the solution was decanted and the fibers were washed with acetone, the solution was again decanted and this was repeated 3 times. The fibers were air dried before analysis of their diameter and length. For certain batches this method was also used to determine the weight fraction of the compounded filaments ( $w t \%)$, according to the following equation 1.

$w t \%=\frac{\text { weight dry fibres after dissolving }}{\text { filament weight }}$

The reduction ratio of the fibers before and after compounding was determined by the ratio of the length, diameter and $1 / \mathrm{d}$ of the fibers after compounding to before compounding.

$2.4 \quad$ Porosity analysis 
Computed Tomography scans were performed on a Phoenix Nanotom 180 device from General Electric. Images were obtained using a Nanotom desktop $\mu \mathrm{CT}$ system. Scans were performed with either a tungsten or a molybdenum target, in mode 1 without filter. For the scans with the tungsten target the voltage was set to $80 \mathrm{kV}$ and the current between $160-170 \mu \mathrm{A}$. With the molybdenum target lower acceleration voltages were possible, the device was set to $45 \mathrm{kV}$ and the current to $181 \mu \mathrm{A}$. To determine the porosity of the scanned filaments, both targets were suitable to perform the tests. Fast scans of 20 minutes were performed with an exposure time of $500 \mathrm{~ms}$. Frame averaging was set to 1 and image skip to 0 . During a scan 2400 images were taken. A filament part of $1 \mathrm{~cm}$ with an average diameter of $2.8 \mathrm{~mm}$ was analyzed, the achieved voxel size was $2 \mu \mathrm{m}$. The data was processed using the 2D/3D image analysis software CTAn (v1.17.7.2) and CTvox (v3.3.0) of Bruker microCT. The 3D porosity measurement is based on the marching cubes volume model [23], and is calculated for $3 \mathrm{~mm}$ of filament length for one sample per material.

\subsection{Contact angle measurements and surface energy analysis}

The advancing and receding contact angles were measured with a Krüss K100 tensiometer using the Wilhelmy technique [24-26]. Film specimens of $20 \mathrm{~mm}$ x $10 \mathrm{~mm}$ x $1 \mathrm{~mm}$ were prepared by pressing the compounded granules at a temperature of $160{ }^{\circ} \mathrm{C}$ and pressure of 20 bar. The contact angle measurements were performed in controlled conditions, with a relative humidity of $60 \%$ and a temperature of $20^{\circ} \mathrm{C}$. The speed used for the dynamic contact angle measurement was set to $2 \mathrm{~mm} / \mathrm{min}$ to a depth of $5 \mathrm{~mm}$. There were 6 different film samples each of cPLA1 and cPLA2, every sample was measured three times in three test liquids: water, ethylene glycol and diiodomethane. Prior to the measurement the films were cleaned with ethanol and rinsed with demineralized water. From the advancing $\left(\theta_{a d v}\right)$ and receding $\left(\theta_{\text {rec }}\right)$ contact angle, the equilibrium contact angle $\left(\theta_{\text {equ }}\right)$ can be calculated according to the work of Andrieu et al. [27] by equation 2.

$\cos \theta_{e q u}=\frac{\cos \theta_{a d v}}{2}+\frac{\cos \theta_{r e c}}{2}$

From the contact angles the acid-base surface free energy components were calculated according to the Van Oss model and by using SurfTen 4.3 software developed by Claudio Della Volpe [28]. To analyze the interfacial strength, the work of adhesion $\left(W_{a}\right)$, the spreading coefficient $(S)$, the wetting tension $(\Delta F)$ and the interfacial energy $\left(\gamma_{s l}\right)$ were calculated. This conforms to the methodology used by Fuentes et al. [25].

$W_{a}=\gamma_{s}+\gamma_{l}-\gamma_{s l}=\gamma_{l}(1+\cos \theta)$ 
$S=\gamma_{s}-\left(\gamma_{l}+\gamma_{s l}\right)$

$\Delta F=\gamma_{s}-\gamma_{s l}=\gamma_{l} \cos \theta$

Where $\gamma_{s}, \gamma_{l}$ and $\gamma_{s l}$ represent the surface energy of the solid, the liquid and the interfacial energy of the solidliquid interface.

The interfacial energy $\left(\gamma_{s l}\right)$ is the reversible work necessary to enlarge the boundary area with a unit area. Minimizing the interfacial energy will result in a more stable system, with an increased adhesive strength.

$\gamma_{s l}=\left(\sqrt{\gamma_{s}^{L W}}-\sqrt{\gamma_{l}^{L W}}\right)^{2}+2\left(\sqrt{\gamma_{s}^{+}}-\sqrt{\gamma_{l}^{+}}\right)\left(\sqrt{\gamma_{s}^{-}}-\sqrt{\gamma_{l}^{-}}\right)$

Equation 6 shows the interfacial energy $\left(\gamma_{s l}\right)$ divided in three components: the Lifshitz-van der Waals $\left(\gamma^{L W}\right)$, an acid $\left(\gamma^{+}\right)$and a base $\left(\gamma^{-}\right)$component.

\subsection{Glass transition determination via differential scanning calorimetry}

Differential scanning calorimetry (DSC) was used to determine the glass transition temperature $\left(T_{g}\right)$ of the different compounds. A DSC Q2000 V24.11 (TA instruments) was used to perform the tests with a temperature cycle based on the ASTM D3418 standard. First a normalization cycle was applied at a heating rate of $10^{\circ} \mathrm{C} / \mathrm{min}$ from $20^{\circ} \mathrm{C}$ to $180^{\circ} \mathrm{C}$ followed by an isothermal stage of 5 minutes and cooling down at $10^{\circ} \mathrm{C} / \mathrm{min}$ to $20^{\circ} \mathrm{C}$. Then, this cycle was repeated and in the second cycle the measurement took place. Nitrogen gas was used to purge the measurement chamber at $50 \mathrm{ml} / \mathrm{min}$. The $T_{g}$ is determined as the midpoint temperature bounded by the tangents to the two flat regions of the heat flow curve. Between 5-12 mg of sample was used to perform the analysis.

\subsection{Tensile tests on the filament and theoretical calculation}

The produced filaments were tested in an oven dry state. Drying was performed in an oven at $60^{\circ} \mathrm{C}$ for at least 1 week. Tests were performed on an Instron 5567 with a load cell of $1 \mathrm{kN}$. The filaments were cut to a length of 9 $\mathrm{cm}$ and had a diameter of approximately $2.85 \mathrm{~mm}$, each specimen's dimensions were measured prior to testing. An extensometer with a gauge length of $25 \mathrm{~mm}$ was used. The composite filaments were tested at a crosshead displacement rate of $2 \mathrm{~mm} / \mathrm{min}$ based on the ASTM D3039 standard. The plastic filaments were tested at a crosshead displacement rate of $20 \mathrm{~mm} / \mathrm{min}$ based on the ASTM D638-03 standard. The stiffness was calculated 
as the slope of the tensile curve between $0.1-0.3 \%$ strain. At least 6 specimens of each compound were analyzed.

The theoretical stiffness of the filaments was calculated based on the rule of mixture $[15,16]$. It is a widely accepted micromechanical model used for calculating modulus of unidirectional, continuous fiber composites as shown in equation 7. With $E$ the modulus, $V$ the volume fraction and the subscripts $c, f$ and $m$ referring to composite, fiber and matrix respectively. The combined rule of mixtures was modified for discontinuous and non-unidirectional fiber orientation composites and an additional term including the effect of porosities was added, leading to equation 8 [16]. Where $\mu_{0}$ is the efficiency factor of the orientation as proposed by Krenchel [29] and $\mu_{l}$ is the efficiency factor of the fiber length that can be calculated by the shear lag model developed by Cox [14]. A more in depth explanation can be found in the work of Madsen et al. [16]. The terms $\mu_{0}$ and $\mu_{l}$ are defined below:

$E_{c}=V_{f} E_{f}+V_{m} E_{m}$

$E_{c}=\left(\mu_{0} \mu_{l} V_{f} E_{f}+V_{m} E_{m}\right)\left(1-V_{p}\right)^{n}$

$\mu_{o}=\sum a_{(i)} \cos ^{4} \theta_{(i)}$

$\mu_{o}=0.2 * a_{(i \text { skin })} \cos ^{4} \theta_{(i s k i n)}+0.8 * a_{(i \text { centre })} \cos ^{4} \theta_{(i \text { centre })}$

$\mu_{l}=1-\frac{\tanh n s}{\mathrm{~ns}}$

With:

$n s=\frac{l}{d} \sqrt{\frac{2 G_{m}}{E_{f} \ln \frac{R}{\mathrm{r}}}}$

The orientation efficiency factor (equation 9) was introduced by Krenchel [29]. Where $a_{(i)}$ is the proportion of parallel fibers in the $i$ th group to the total amount of fibers and $\theta_{(i)}$ the angle of the fibers with respect to the loading direction in the $i$ th group. For unidirectional loaded fibers $\mu_{0}=1$, for $2 \mathrm{D}$ random orientation $\mu_{0}=0.375$ and for $3 \mathrm{D}$ random orientation $\mu_{0}=0.2$. 
The orientation of the fibers in the filament was determined from microscopy images. Three pieces of randomly sampled filament, $2 \mathrm{~cm}$ in length, were embedded, sanded and polished till halfway. Pictures were taken with a Wild M8 stereomicroscope (Wild Heerbrugg). From the cross sections it could be seen that the fibers at the skin region were highly oriented (aligned with the outer skin) while the fibers at the center region less. A separation between skin and center region was made, with $0.2 *$ filament diameter identified as the outer region and the remaining $0.8 *$ filament diameter as the center region. The angle of at least 51 and 34 fibers was measured in the center and in the skin region, respectively. A histogram of the angles for each region was plotted and an orientation factor per region was determined. In order to calculate the total $\mu_{0}$, the same weight fraction was used based on the area occupied on the cross sectional images, resulting in equation 10 .

The shear lag model developed by Cox $[14,30]$, led to the definition of the length efficiency factor $\mu_{l}$ as proposed in equation 11-12. Where $l(\mathrm{~m})$ is the fiber length, $d(\mathrm{~m})$ the fiber diameter, $G_{m}(\mathrm{GPa})$ the shear stiffness of the matrix and the value $\frac{R}{r}$ depending on the fiber packing [30]. For square packing $\frac{R}{r}=\sqrt{\frac{\pi}{V_{f}}}$ and for hexagonal packing $\frac{R}{r}=\sqrt{\frac{2 \pi}{\sqrt{3} V_{f}}}$. The $1 / \mathrm{d}$ is measured directly on the fibers as it was discussed in section 2.3.

The effect of porosity can be included in the rule of mixtures with the factor $\left(1-V_{p}\right)^{n}$, as it was proposed in the work of Madsen et al. [16]. Where $n$ is the porosity efficiency exponent and $V_{p}$ the porosity volume fraction. The exponent $n$ quantifies stress concentrations in the composite due to the porosity. Madsen et al. [31] experimentally concluded that a porosity exponent, $n=2$, typically gives a good fit for plant fibers. The porosities of the filaments were measured via computed tomography (CT) scans, as it was explained in section 2.4 .

In short fiber mechanics, the critical length, $l_{c}$, is an important factor. For a given fiber diameter, at this critical fiber length the maximum fiber stress can be reached in the short fiber and tensile failure of the fiber can occur. $l_{c}(\mathrm{~mm})$ is defined as in equation 13 , with $\sigma_{f}(\mathrm{MPa})$ the ultimate fiber tensile strength and $\tau(\mathrm{MPa})$ the interfacial shear strength (IFSS) and $d(\mathrm{~mm})$ the diameter.

$l_{c}=\frac{\sigma_{f} d}{2 \tau}$

Viel [32] examined the IFSS between PLA and bamboo by fiber pull-out tests and came to a range of 3.9-10.1 MPa. Wong et al. [33] reported the IFSS of PLA and flax fibers to be in the range of 6-12 MPa. For the 
1

2

3

4

5

6

7

8

9

10

calculations of this work a mean value of these is used, $\tau=7 \mathrm{MPa}$ for bamboo PLA and $\tau=9 \mathrm{MPa}$ for flax PLA. For the fiber strength, back calculated strength values are used from the work of Bensadoun et al. [34] for flax, and from the work of Trujillo [35] for bamboo. The diameters of the fibers were measured in this work as explained in section 2.3 .

The average fiber stress $\overline{\sigma_{f}}(\mathrm{MPa})$ in the short fiber reinforced composite can be calculated either by equation 14 or 15 depending on the length of the fiber [36].

$l \leq l_{c}: \quad \overline{\sigma_{f}}=\frac{\tau l}{d}$

$l>l_{c}: \overline{\sigma_{f}}=\left[1-\left(\frac{l_{c}}{2 l}\right)\right] \sigma_{f}$

\subsection{SEM}

Scanning electron microscopy was used to analyze the fracture surfaces in order to study the failure behavior. Pictures were made with a Philips XL30 FEG electron microscope in secondary electrons mode with a voltage of $10 \mathrm{kV}$. The samples were prepared by sputtering the surface with gold-palladium (Au-Pd).

\section{Results and Discussion}

\subsection{Effect of compounding on $1 / \mathrm{d}$ of fiber}

Figure 3 shows the length and diameter distribution of the different fiber fractions before compounding. Fraction B1 and B2 have the shortest fibers with the smallest diameter and this is as expected from the appearance of the batch which is more dust-like before compounding. Instead, fraction B3 and B4 consist out of clearly distinguishable fibers before compounding. Length analysis shows that they have comparable length, but fraction B3 has a larger mean diameter which will result in a lower length over diameter ratio (1/d). Furthermore, it can be seen that the flax fibers were indeed cut to the targeted lengths of $2 \mathrm{~mm}$ and $5 \mathrm{~mm}$. Table 1 lists the median of the length and diameter distribution of each fraction along with the corresponding 1/d ratio before compounding. Fractions B3, B4, F1 and F2 are referred to as the long fiber fractions.

The fibers were compounded into a PLA matrix with two different PLA plasticizers, referred to as cPLA1 and cPLA2. After compounding, the matrix was dissolved and the compounded fibers were dried and analyzed via the same length and diameter determination method. This method was only applicable for the fiber fractions B3 and B4, with sufficient length, for shorter fractions it was impossible to separate the dust from the dissolved 
PLA. Also for the flax fractions more difficulties were encountered during dissolving, since it seemed that the fibers became much smaller, which led to the loss of small particles during decanting, leading to an overestimation of 1 and 1/d for F1. Because of this, F2 was not analyzed. Figure 4 shows the length and fiber distribution of the fiber fractions B3, B4 and F1 after compounding in the two PLA systems while Table 2 lists the $1 / \mathrm{d}$ ratio and the reduction ratio as a result of compounding.

\subsubsection{Effect of the extruder rotational velocity and PLA type}

B3cPLA1 was compounded at $200 \mathrm{rpm}$ while B3cPLA2 was compounded at $350 \mathrm{rpm}$, and B4cPLA1 and B4cPLA2 were both compounded at $350 \mathrm{rpm}$. Comparing the two B4 filaments it is clear that the type of PLA does not influence the final fiber dimensions. However, the rotation speed of the extruder does. A lower rotation speed results in longer fibers with a larger diameter. On the other hand, a rotation speed of $200 \mathrm{rpm}$ was not ideal since it led to a rougher surface of the filament. The hypothesis is that at $200 \mathrm{rpm}$ the mixing of the fiber into the polymer is not sufficiently homogeneous. By increasing the angular velocity (or rotational speed) of the screw, the polymer becomes less viscous, due to shear thinning, which results in enhanced wetting between fiber and polymer.

Comparing the dimensions of the fiber of batches B3 and B4 after compounding, it is seen that the pronounced difference before compounding has decreased. This indicates that the setup of the extruder limits the maximum achievable fiber length. Adding longer fibers does not necessarily yield longer fibers in the final filament.

Taking a closer look at Table 2, which shows the reduction ratio of the fibers, it is observed that the flax fiber diameter has fallen back to $27.4 \%$ of the original diameter. In contrast, the bamboo diameter is still between 60 $100 \%$ of the original one. The resulting median diameter of the flax fibers is $42 \mu \mathrm{m}$; this reduction explains the difficulties during decanting. Several authors [37-40] characterized flax fibers and made the distinction between technical and elementary fibers. Diameters of technical fibers, also referred to as fiber bundles range between $50-135 \mu \mathrm{m}[37,40]$. Elementary fibers have a diameter of around 10-25 $\mu \mathrm{m}$ [37-40]. In this experiment, the compounded technical flax fibers are separated into smaller bundles of elementary fibers, by the shear forces developed in the compounder. This occurs as the elementary flax fibers in the technical fibers are connected by middle lamellae. These middle lamellae consist out of amorphous polymers such as hemicellulose and pectin which have a very low shear strength, resulting in partial disintegration of the technical fiber. This phenomenon is less likely to occur in technical bamboo fibers as a much stronger, three dimensional network of lignin holds 
the elementary fibers together [41]. Splitting of technical flax fibers was also found in other studies $[42,43]$. The result after the compounding step is that flax has a higher $1 / \mathrm{d}$, due to the reduced diameter.

\subsubsection{Calculation of the length efficiency factor}

Based on the length to diameter aspect ratios in the filament, the fiber length efficiency factor can be calculated using equation 11 and 12. For fractions B1 and B2 it was assumed that the length to diameter ratio before compounding did not change during compounding. The degradation in length and diameter of these dust fractions would be small. In equation 12 , suitable natural fiber values were used; $E_{\text {flax }}=60 \mathrm{GPa}$ [34], and $E_{\text {bamboo }}=40 \mathrm{GPa}[35], G_{m}=1 \mathrm{GPa}[16], \frac{R}{r}=\sqrt{\frac{2 \pi}{\sqrt{3} V_{f}}}$ [30] and $V_{f}=0.135$ (recalculated from weight fraction). Table 3 lists the calculated fiber length efficiency factors; they will be used later on to calculate the theoretical stiffness of the filaments. The maximal fiber length efficiency factor is 1 when the fibers are continuous. For the filaments reinforced with the long fibers (B3-B4) this means that around $18 \%$ of the stiffness of a continuous fiber is transferred into the composite; for the flax fiber (F1) this value increases to $30 \%$.

\subsection{Filament characterization \\ 3.2.1 Verification of the filament weight fraction}

Three fractions were chosen to determine the weight fraction of the compounded fibers. The filaments were first dissolved, in the same way as for the fiber characterization after compounding, then the fibers were dried and weighed. The compounder was set to $15 \mathrm{wt} \%$ of fibers. The experimental data, shown in Table 4 , give values that are a bit lower, but are close enough to the targeted value. A remark should be made that by decanting it is easy to lose some of the small fibers, since they tend to float on top of the solution, underestimating the actual weight fraction.

\subsubsection{Porosity characterization of the produced filaments}

\section{Effect of vacuum}

The influence of applying vacuum at the end of the compounding line was assessed. Figure 5 shows the influence of the vacuum pump on the porosity inside the filament. The round shape outlines the filament, with in dark grey the porosities and in light grey some fibers are visible. From the pictures it can be seen that the 
vacuum lowers the porosity to below the voxel size being used $(2 \mu \mathrm{m})$. Therefore no porosities could be measured. This indicates the importance of applying vacuum at the end of the screw metering zone. For the production of the other filaments, vacuum was applied.

Effect of drying

Figure 6 shows cross-sections of all the different filaments produced and scanned via CT scanning. Though all filaments were produced with the vacuum pump on, there is still a difference in porosity. Fiber fractions for the compounding of filaments B3cPLA2, B4cPLA1 and B4cPLA2 were dried in a vacuum oven before compounding and the other filaments in a Moretto hot air dryer. This research shows that a hot air dryer is more effective in removing all moisture out of the fiber fractions. For production purposes this would be the method of choice.

All filaments produced in this research contain less porosities than the commercially available filament. By foreseeing adequate drying the porosities can be lowered to levels between $0-4 \%$.

\subsubsection{Orientation efficiency factor}

Based on the distribution of the measured angles by equation 10 the orientation efficiency factors are calculated and shown in Table 5. The microscopic images in Figure 7 show the orientation of some filaments while Figure 8 shows an example of how the angles were measured and the histograms that were made for the skin and center region. Figure 7 also gives insight in the structure of the dust like fractions after compounding. Where an increasing particle aspect ratio is seen when going from the reference, to B1cPLA and B2cPLA1 filament.

As it can be noted in Table 2 the length and diameter of the flax fibers is drastically reduced. In the picture, it is also clear that the flax fibers are curved due to compounding; this is expected to have an influence on the stiffness of the filaments. For the dust like bamboo reinforced fractions B1-B2, the orientation of the fibers could not be determined, and a 2D random orientation was assumed, as well as for the flax filament, where $\mu_{0}=$ $0,375[16]$.

3.3 Tensile tests on the filament and theoretical prediction 
Table 6 lists the results of the tensile tests performed on the filaments. The modulus of the experimental tests $E_{\text {exp }}$ is presented as well as the theoretical modulus $E_{t h}$ calculated by equation 8, taking into account the fiber length efficiency factor, the orientation efficiency factor and the porosity factor. The increase in stiffness by adding fibers to the cPLAx was calculated as $\frac{E_{\text {exp }}-E_{C P L A x}}{E_{c P L A x}}$ and a theoretical efficiency factor was defined as $\frac{E_{e x p}}{E_{t h}}$. In the former equation, $E_{C P L A x}$, represents the modulus of the cPLA1 or cPLA2 polymer.

The modulus of the cPLAx was lower than that of the virgin polymer. cPLA1 has only $30 \%$ of the stiffness of the pure PLA and cPLA2 19\%. When the stiffness of the printed FDM part is critical, cPLA1 should be preferred over cPLA2.

All filaments show a stiffness improvement in relation to cPLAx when they are compounded with fibers, as shown in the fourth column of Table 6 . The highest reinforcement is found for the filaments containing long bamboo fibers, where an increase between $91 \%$ and $230 \%$ in modulus is seen. Despite the higher $1 / \mathrm{d}$ ratio of the flax fibers this does not lead to a larger increase in stiffness, due to the loss in orientation because of fiber curvature in the compounding process. The smallest reinforcement effect is found for the bamboo dust fractions B1 and B2, where an improvement of only 22 and 39\%, respectively, could be found. Overall an increasing modulus is found with increasing $1 / \mathrm{d}$ ratio which is in agreement with the theory.

B4cPLA1 and B4cPLA2 show higher experimental stiffness values than B3cPLA2 due to the higher 1/d ratio. The goal of this research was to reach the same or higher stiffness as the reference filament by using plasticized PLA reinforced with longer fibers. With the long fiber reinforcements this goals was reached, except for the F2cPLA1. The experimental modulus of the F2cPLA1 filament is lower than for the F1cPLA1 filament, while both of them have a comparable porosity. From this it can be deduced that the $1 / \mathrm{d}$ ratio inside the F2cPLA1 filament is of the same order as for the F1cPLal filament.

For the dust-like fractions $E_{t h}$ was based on the 1/d before compounding. For all other fractions, the calculations were performed based on the 1/d ratio after compounding. The theoretical modulus for F2cPLA1 and the reference filament was not calculated since the $1 / \mathrm{d}$ after compounding was not determined. Comparing the theoretical modulus with the experimental modulus, it is seen that for all bamboo filaments the experimental modulus exceeds the theoretical modulus with the $E_{\text {exp }}$ being 1.20-2.46 times $E_{t h}$. This means that the parameters for the theoretical model are an underestimate of the reality. Analyzing equation 8-12 only a few 
parameters can be determined to be responsible for an underestimation of the modulus: $V_{p}, n, \mu_{0}, \mu_{l}$. Considering realistic values of each of these parameters, and varying the values, points out that a change in porosity, $n$ or $\mu_{0}$ is not able to account for this underestimation. However a tripling of the $\mu_{l}$ increases the $E_{t h}$ to values close to and exceeding $E_{\text {exp }}$. In section 3.1.2 $\mu_{l}$ was calculated assuming some default values, where $G_{m}$ might be underestimated or the packing overestimated. Further research should be conducted to analyze this deviation of the experiments from the shear lag model.

The highest theoretical modulus was predicted for the bamboo reinforced B3cPLA1 at 1.78 GPa. This is due to the low porosity of $0.3 \%$ and high $1 / \mathrm{d}$ ratio of 4.72 combined with a high fiber orientation efficiency in the filament. However, the experimental stiffness of the filament is lower than for the other long bamboo fiber filaments. This is related to the low rotational velocity used for this filament, which led to insufficient mixing and bad wetting. Due to this, the modulus of B3cPLA1 is even lower than for B3cPLa2, which is not expected because of the differences between the two PLA's and the comparable 1/d ratios.

Figure 9 shows the ultimate tensile strength and failure strain of the filaments. The tensile strength of cPLA1 and cPLA2 respectively is $31 \pm 3 \mathrm{MPa}$ and $26 \pm 2 \mathrm{MPa}$.

The critical fiber length to diameter ratio for bamboo and flax fibers was determined according to equation 13 . For bamboo $\frac{l_{c}}{d}=35.3$ (with $\tau=7 \mathrm{MPa}[32], \sigma_{f}=494 \mathrm{MPa}$ [35]) and for flax $\frac{l_{c}}{d}=29.3$ (with $\tau=9 \mathrm{MPa}$ [33], $\sigma_{f}$ $=527 \mathrm{MPa}$ [34]). Comparing these values with the measured $1 / \mathrm{d}$ after compounding it is clear that the critical fiber length is not reached and the average fiber stress can be calculated according to equation 14 , for the case where $l<l_{c}$. In the case of bamboo with an $1 / \mathrm{d}$ ranging between $4.12-4.72$, the average stress in the fiber ranges from 29-33 MPa ( $\tau=7 \mathrm{MPa}[32])$. These values are in the same order as the strength of the polymer and therefore the fibers with this $1 / \mathrm{d}$ will hardly be able to reinforce the filament. For flax an $1 / \mathrm{d}$ of 8.38 was measured ( $\tau=9 \mathrm{MPa}[33])$ leading to an average stress in the fiber of $75 \mathrm{MPa}$. This stress represents theoretically only $0.14 \%$ of the maximum fiber stress applicable in a continuous fiber composite (75/494). Experimental confirm this by showing that adding fibers did not increase the ultimate tensile strength to a value higher than the corresponding PLA. In some cases the strength is even lowered, caused by the fibers that act as defects and introduce stress concentrations; the same phenomena lowers the strain to failure of the filaments drastically. 
The second graph of Figure 9 shows the tensile failure strain achieved in the filaments. The filaments have a strain to failure of at least 12 times lower than the corresponding cPLAx. It can also be found that longer fibers lead to lower failure strains, since the fibers act as defect and a larger fiber corresponds to a larger defect. For the dust like reinforced filament B2cPLA1 a failure strain $(\mathrm{mm} / \mathrm{mm})$ of $13 \pm 4 \%$ could be found.

\subsection{Fiber-matrix interface characterization}

The advancing, receding and equilibrium contact angles were measured with 3 liquids. Surface energy calculation are based on the equilibrium contact angle by equation 2 and the results are shown in Table 7.

The surface energy components of bamboo and flax fiber were taken from literature $[25,44]$ and were calculated for the 2 types of compounded PLA using the measured contact angles and are shown in Table 8 . Table 9 shows the interfacial wetting parameters between bamboo, flax and the 2 types of compounded PLA which are calculated using the equations 3-6.

Research conducted by Biresaw et al. [45] found for the total surface energy of PLA $\gamma=43.5 \frac{\mathrm{mJ}}{\mathrm{m}^{2}}$. In this research $41.40 \frac{\mathrm{mJ}}{\mathrm{m}^{2}}$ and $41.78 \frac{\mathrm{mJ}}{\mathrm{m}^{2}}$ are found for cPLA1 and cPLA2 respectively. The small differences can be due to the amount of plasticizer and the base type of PLA.

For bamboo and flax compounds, the differences in $W_{a}$ are not significant. The values are high so the adhesive strength between fiber and matrix is predicted to be good. However, the spreading coefficient is somewhat negative which hinders the spontaneous wetting of the fibers in the molten polymer. This negative $S$ leads to partial spreading and makes it suboptimal to make fiber reinforced composites. The spreading could be improved by creating a cPLAx with more acid groups in the plasticizer or PLA; this will increase $\gamma^{+}$and could make $S$ positive while maintaining a high $W_{a}$ and $\Delta F$. From the analysis of all wetting parameters it is concluded that cPLA1 and cPLA2 have no distinguishable difference in the wetting of the natural fibers.

\subsection{Fracture surface}

Figure 10 shows the images of the fracture surfaces of the filaments obtained by SEM. The images show a homogeneous dispersion of the fibers in the filament. The images of the fracture surface of B3cPLA1 (A) and (B) reveal that the fibers are pulled out of the matrix. The critical $\frac{l_{c}}{d}$ is not reached preventing fiber failure from occurring. The fracture surface shows brittle failure of the polymer matrix, but fiber pull-out will contribute to 
toughness. For the dust-like fiber sample B1cPLA1, images (C)-(D), a ductile failure was found distinguishable by the dimples in the surface, reminiscent of ductile failure of the polymer matrix.

\subsection{Glass transition temperature}

The thermal behavior of filaments is of crucial importance in FDM, being responsible for the bonding between the extruded molten filament an the previous, already solid, deposited material. Throughout the FDM printing the filaments are cooling down from the melt temperature, $T_{m}$ to the glass transition temperature, $T_{g}$. During cooling, contraction of the matrix surrounding the fibers occurs, though internal stresses mainly accumulate during cooling down from $T_{g}$ to print chamber temperature. When the difference between the Tm and the $T_{g}$ is too large, the temperature of the filament will decrease rather slowly and deformation can occur upon deposition [46].

The glass transition temperature $\left(T_{g}\right)$ of the filaments are shown in Table 10. In the case of cPLA1 the glass transition temperature decreases with $35 \%$ and in the case of cPLA2 with 53\% compared to the virgin polymer. The change in $T_{g}$ when $15 \mathrm{wt} \%$ fibers are added is not significantly different. Different added fractions give rise to a different change in $T_{g}$. Though for all the compounded filaments in cPLA1 the temperature stays in the range of $37.6-41.9^{\circ} \mathrm{C}$ for cPLA2 this is much lower, ranging between $27.1-27.6^{\circ} \mathrm{C}$.

For the produced filaments with cPLA2, $T_{g}$ is extremely low which can cause shrinkage problems and low technical stability due to the low $T_{g}$. A solution to increase the $T_{g}$ is adding less plasticizer. Future work will optimize the printability of a few of the produced filaments with cPLA1.

\subsection{Demonstrator part}

A demonstrator part was printed to demonstrate the applicability of this novel material. In Figure 11 two brake levers, one printed out of B2cPLA1 and one out of F1cPLA1, are shown. The parts were mounted on the 王BIKE [47]. A creation of 15 Flemish (Belgium) 3D printing companies and research institutions with as goal to showcase the existing 3D printing technologies and the added value that can be created. Printing was conducted on a low-end 3D printer, after nozzle adaptation. Process parameters were in the usual range of temperature (around $180^{\circ} \mathrm{C}$ ) and axes travel speed (around $20 \mathrm{~mm} / \mathrm{s}$ ). In future research, the 3D printing parameters for these two compounds will be optimized. 


\section{Conclusions}

The goal of this research was to reinforce filaments for FDM with natural fiber fractions and to investigate the effect of different $1 / \mathrm{d}$ ratios in order to increase their stiffness. The filaments were compounded with flax and bamboo fibers and high quality filaments with only $0-4 \%$ of voids could be produced. No influence of plasticizer type could be found on the $1 / \mathrm{d}$ of the fibers after compounding. However, an effect of the extruder rotational speed was seen. A low rotational speed of $200 \mathrm{rpm}$ resulted in a higher $1 / \mathrm{d}$ ratio after compounding but a rougher filament surface was obtained, which was considered to be unsuitable for FDM. Higher rotational speed of $350 \mathrm{rpm}$ led to a smoother surface and were preferred.

The length over diameter ratio of the compounded fibers showed an influence on the modulus of the filament. Reinforcing the PLA filament with long bamboo fibers increased the stiffness by $215 \%$, whereas the dust like fractions showed an increase of only $39 \%$, this is in agreement with the theory on short fiber mechanics. No strength increase could be seen due to the low $1 / \mathrm{d}$ of the fibers. Changes to the compounding line in order to have longer fibers in the filament, would be an interesting route to investigate.

By characterizing the $1 / \mathrm{d}$ of the filament after compounding, analyzing the orientation of the fibers inside the filament and measuring the porosities, the theoretical fiber modulus was calculated. However, in this research the theoretical model did not predict the experimental data very well, with the theoretical modulus underestimating the experimental one. Further research is needed to explain this difference.

Wetting experiments showed that the two compounded PLA types are expected to have rather good interfacial compatibility with both flax and bamboo. However, no difference between the two PLA types could be found regarding the bonding. A difference could be seen analyzing the $T_{g}$, with a probably too low $T_{g}$ for cPLA2 which indicates cPLA1 as the better choice for 3D printing.

Future research will focus on the optimization of the printing process with the produced filaments B2cPLA1 and F1cPLA1, and their applications.

\section{Acknowledgements}


The authors thank the Impulse Fund KU Leuven - Belgium (BOF/IMP14/034) as well as the Agency for Innovation and Entrepreneurship Flanders via the Strategic Initiative Materials in Flanders in the framework of the SIM-ICON FlaxPreComp project (IWT 140149). The authors would also like to acknowledge Karen Soete for her help with the fiber length characterization and Eleonora Ferraris, Frederik Vogeler, Hans De Punt and Mathilde Armand for the development of the demonstrator parts.

\section{References}

[1] J. Cerneels, A. Voet, J. Ivens, J.-P. Kruth, Additive manufacturing of thermoplastic composites, Composites week@ Leuven, Leuven, Belgium(2013).

[2] B. N. Turner, R. Strong, S. A. Gold, Rapid Prototyping Journal, 20, 3 (2014).

[3] N. Guo, M. C. Leu, Frontiers of Mechanical Engineering, 8, 3 (2013).

[4] G. Alaimo, S. Marconi, L. Costato, F. Auricchio, Composites Part B-Engineering, 113 (2017).

[5] A. Bellini, S. Guceri, Rapid Prototyping Journal, 9, 4 (2003).

[6] M. Spoerk, F. Arbeiter, H. Cajner, J. Sapkota, C. Holzer, Journal of Applied Polymer Science, 134, 41 (2017).

[7] N. Mohan, P. Senthil, S. Vinodh, N. Jayanth, Virtual and Physical Prototyping, 12, 1 (2017).

[8] S. H. Masood, W. Q. Song, Materials \& Design, 25, 7 (2004).

[9] F. D. Ning, W. L. Cong, J. J. Qiu, J. H. Wei, S. R. Wang, Composites Part B-Engineering, 80 (2015).

[10] A. D. Van Wijk, I. Van Wijk, 3D printing with biomaterials, Amsterdam, The Netherlands: IOS Press, (2015).

[11] S. Singh, S. Ramakrishna, R. Singh, Journal of Manufacturing Processes, 25 (2017).

[12] J. Šafka, M. Ackermann, J. Bobek, M. Seidl, J. Habr, L. Bĕhálek, Materials Science Forum, 862 (2016).

[13] M. Kariz, M. Sernek, M. Obućina, M. K. Kuzman, Materials Today Communications, 14 (2018).

[14] H. L. Cox, British Journal of Applied Physics, 3, 3 (1952).

[15] A. Kelly, N. H. Macmillan, Strong solids, 3rd ed. ed: Oxford University Press, (1986).

[16] B. Madsen, A. Thygesen, H. Lilholt, Composites Science and Technology, 69, 7-8 (2009).

[17] K. Oksman, M. Skrifvars, J. F. Selin, Composites Science and Technology, 63, 9 (2003).

[18] D. Stoof, K. Pickering, Y. Zhang, Journal of Composites Science, 1, 1 (2017).

[19] K. Hendrickx, R. Romian, T. Goedemé, A. Van Vuure, J. Ivens, Rapid and effective methods for the screening of flax fibers for composite applications., International Conference on Composite Materials (ICCM) Copenhagen, Denmark(2015).

[20] F. Desplentere, K. Soete, H. Bonte, E. Debrabandere, Local mechanical properties of LFT injection molded parts: numerical simulations versus experiments, PPS edition 29, Nuremberg, Germany(2013).

[21] F. Desplentere, K. Soete, L. Vandenweghe, H. Bonte, E. Debrabandere, Fiber length along injection molding screw, Polymer Molds and Innovations edition 5, Ghent, Belgium(2012), p. 69-75.

[22] B. E. Huapeng Wang, Fiber property characterisation by image processing [Master thesis]: Texas Tech University, (2007).

[23] W. E. Lorensen, H. E. Cline, SIGGRAPH Comput Graph, 21, 4 (1987).

[24] C. A. Fuentes, L. Q. N. Tran, C. Dupont-Gillain, W. Vanderlinden, S. De Feyter, A. W. Van Vuure, I. Verpoest, Colloids and Surfaces a-Physicochemical and Engineering Aspects, 380, 1-3 (2011).

[25] C. A. Fuentes, L. Q. N. Tran, M. Van Hellemont, V. Janssens, C. Dupont-Gillain, A. W. Van Vuure, I. Verpoest, Colloids and Surfaces a-Physicochemical and Engineering Aspects, 418 (2013).

[26] C. A. Fuentes, G. Brughmans, L. Q. N. Tran, C. Dupont-Gillain, I. Verpoest, A. W. Van Vuure, Composites Science and Technology, 109 (2015).

[27] C. Andrieu, C. Sykes, F. Brochard, Langmuir, 10, 7 (1994).

[28] C. Della Volpe, M. Brugnara, D. Maniglio, S. Siboni, T. Wangdu, About the possibility of experimentally measuring an equilibrium contact angle and its theoretical and practical consequences(2006).

[29] H. Krenchel, Fiber reinforcement: theoretical and practical investigations of the elasticity and strength of fiber-reinforced materials, Copenhagen, Denmark: Akademisk forlag, (1964).

[30] M. Piggott, Load bearing fiber composites, New York, USA: Kluwer Academic Publishers, (2002).

[31] B. Madsen, Properties of plant fiber yarn polymer composites - an experimental study. [PhD Thesis]: Technical University of Denmark, (2004).

[32] Q. Viel, Interface properties of bio-based composites of polylactic acid and bamboo fibers [Master Thesis]: University of Nebraska-Lincoln, (2013). 
[33] S. Wong, R. A. Shanks, A. Hodzic, Composites Science and Technology, 67, 11 (2007).

[34] F. Bensadoun, I. Verpoest, J. Baets, J. Müssig, N. Graupner, P. Davies, M. Gomina, A. Kervoelen, C. Baley, Journal of Reinforced Plastics and Composites, (2017).

[35] E. Trujillo, Polymer composite materials based on bamboo fibers [PhD thesis], Leuven: KU Leuven, (2014).

[36] F. L. Matthews, R. D. Rawlings, Composite materials: Engineering and science, Cambridge, England: Woodhead Publishing Limited, (1994).

[37] S. Alix, L. Lebrun, S. Marais, E. Philippe, A. Bourmaud, C. Baley, C. Morvan, Carbohydrate Polymers, 87, 1 (2012).

[38] A. Bourmaud, C. Morvan, A. Bouali, V. Placet, P. Perre, C. Baley, Industrial Crops and Products, 44 (2013).

[39] A. Lefeuvre, A. Bourmaud, L. Lebrun, C. Morvan, C. Baley, Industrial Crops and Products, 50 (2013).

[40] H. L. Bos, M. J. A. Van Den Oever, O. Peters, Journal of Materials Science, 37, 8 (2002).

[41] K. Charlet, A. Beakou, International Journal of Adhesion and Adhesives, 31, 8 (2011).

[42] F. Puch, C. Hopmann, Polymer Composites, 36, 12 (2015).

[43] K. Soete, F. Desplentere, S. V. Lomov, D. Vandepitte, Journal of Composite Materials, 51, 23 (2017).

[44] L. Q. N. Tran, C. A. Fuentes, I. Verpoest, A. W. Van Vuure, Interfacial Compatibility and Adhesion in Natural Fiber Composites, In: Campilho RDSG, editor, Natural Fiber Composites, Boca Raton, USA: CRC Press Taylor \& Francis Group, (2016).

[45] G. Biresaw, C. J. Carriere, Journal of Polymer Science Part B: Polymer Physics, 40, 19 (2002).

[46] T. M. Wang, J. T. Xi, Y. Jin, International Journal of Advanced Manufacturing Technology, 33, 11-12 (2007).

[47] Flam3d, 王-BIKE, https://www.flam3d.be/王-bike/.

\section{Tables and Figures}

Table 1 The median of the length and diameter for each fraction and the $1 / \mathrm{d}$ ratio before compounding

Table 2 The median of the length and diameter of each fraction and the 1/d ratio after compounding. With shortening defined as the ratio of the considered parameter after compounding over before compounding, with $l$ length and $d$ diameter

Table 3 The fiber length efficiency factors calculated on the length to fiber diameter ratios

Table 4 The calculated weight fractions of some filaments to check the accuracy of the extruder

Table 5 The orientation efficiency factor calculated from the fiber angle measurements by equation 9

Table 6 The theoretical modulus compared to the experimental modulus of the filaments and their improvements

Table 7 The measured advancing, receding and equilibrium contact angles in combination with water (WT), ethylene glycol (EG) and Diiodomethane (DIO). The velocity of the measurements was $2.0 \mathrm{~mm} / \mathrm{min}$. Each measurement is the mean of 6 samples who are measured 3 times

Table 8 The acid-base approach of the surface energy components of Bamboo fibers, flax fibers and 2 types of compounded PLA.

Table 9 The wetting parameters between bamboo and flax with 2 types of compounded PLA.

Table 10 The glass transition temperatures of the produced and reference filaments

Figure 1 Screw profile and temperature settings of the Leistritz ZSE 18 MAXX 36D compounder, with 36 segments of length equal to the screw diameter D

Figure 2 Illustration of the boxplots

Figure 3 Boxplot of the fiber length and diameter distribution of the different fiber fractions before compounding, measured by an automated image processing algorithm

Figure 4 Boxplot of the fiber length and diameter distribution of the fiber fractions B3, B4 and F1 after compounding, measured by an image processing algorithm. Fractions B1, B2 and F2 were not measured due to difficulties during dissolving, related with to the particle dimensions

Figure 5 Influence of vacuum on the filament porosity

Figure 6 Porosities of the different produced filaments. The dark grey areas are air, the light grey areas are fibers and the grey area is the matrix

Figure 7 Microscopic pictures of a longitudinal cross section of (a) the Reference filament, (b) the B1cPLA1 filament, (c) the B2cPLA1 filament and (d) the F1cPLA1 filament and (e) the B3cPLA1 filament. The Reference, F1, B1 and B2 fibers show random orientation 
Figure 8 Microscopic picture of the B4cPLA2 filament, with indication of the center and skin region as well as some indicated fiber angle measurements and the two according histograms

Figure 9 Results of the tensile tests for the ultimate tensile strength and failure strain of the different filaments considered

Figure 10 The scanning electron microscope pictures of (a) the B3cPLA1 filament, (b) a close-up of B3cPLA1 filament, (c) B1cPLA1 filament and (d) a close up of the B1cPLA1 filament

Figure 11 (a) Demonstrator brake lever printed out of B2cPLA mounted on the王-BIKE (Photographer: Filip Van Loock, 2016), (b) Brake lever part printed out of B2cPLA1 and F1cPLA1 
1

2

3

4

5

6

7

8

9

10

11

12

13

14

15

16

17

18

19

20

21

22

23

24

25

26

27

28

29

30

31

32

33

34

35

36

37

38

39

40

41

42

43

44

45

46

47

48

49

50

51

52

53

54

55

56

57

58

59

60

Table 1 The median of the length and diameter for each fraction and the $1 / \mathrm{d}$ ratio before compounding

\begin{tabular}{llll} 
& Length $(\mu \mathrm{m})$ & Diameter $(\mu \mathrm{m})$ & $1 / \mathrm{d}$ \\
\hline B1 & 124 & 47 & 2,64 \\
B2 & 218 & 95 & 2,30 \\
B3 & 2015 & 254 & 7,93 \\
B4 & 2140 & 152 & 14,08 \\
F1 & 1870 & 153 & 12,22 \\
F2 & 4849 & 120 & 40,41
\end{tabular}

John Wiley \& Sons 
Table 1 The median of the length and diameter of each fraction and the 1/d ratio after compounding. With shortening defined as the ratio of the considered parameter after compounding over before compounding, with $l$ length and $d$ diameter

\begin{tabular}{llll|lll} 
& & & & \multicolumn{3}{|l}{ Reduction ratio } \\
\cline { 5 - 6 } & Length $(\mu \mathrm{m})$ & Diameter $(\mu \mathrm{m})$ & $1 / \mathrm{d}$ & $\frac{l_{\text {after }}}{l_{\text {before }}}$ & $\frac{d_{\text {after }}}{d_{\text {before }}}$ & $\frac{l}{d}$ \\
& & & & & & $\frac{l}{l}$ after \\
\hline B3 cPLA1 & 893 & 189 & 4,72 & $44.3 \%$ & $74.4 \%$ & $59.5 \%$ \\
B3 cPLA2 & 629 & 153 & 4,12 & $31.2 \%$ & $60.2 \%$ & $52.0 \%$ \\
B4 cPLA1 & 627 & 134 & 4,68 & $29.3 \%$ & $88.1 \%$ & $33.2 \%$ \\
B4 cPLA2 & 713 & 153 & 4,67 & $33.3 \%$ & $100 \%$ & $33.2 \%$ \\
F1 cPLA1 & 355 & 42 & 8,38 & $19.0 \%$ & $27.4 \%$ & $68.6 \%$
\end{tabular}


Table 1 The fiber length efficiency factors calculated on the length to fiber diameter ratios

\begin{tabular}{ll} 
Filament & $\mu_{l}$ \\
\hline B1 cPLA1 & 0.07 \\
B2 cPLA1 & 0.05 \\
B3 cPLA1 & 0.18 \\
B3 cPLA2 & 0.14 \\
B4 cPLA1 & 0.18 \\
B4 cPLA2 & 0.17 \\
F1 cPLA1 & 0.30
\end{tabular}


Table 1 The calculated weight fractions of some filaments to check the accuracy of the extruder

\begin{tabular}{ll} 
Filament & $\mathrm{wt} \%$ \\
\hline B3 cPLA2 & 13.7 \\
B4 cPLA1 & 12.7 \\
B4 cPLA2 & 12.7
\end{tabular}

10

11

12

13

14

15

16

17

18

19

20

21

22

23

24

25

26

27

28

29

30

31

32

33

34

35

36

37

38

39

40

41

42

43

44

45

46

47

48

49

50

51

52

53

54

55

56

57

58

59

60

John Wiley \& Sons 
1

2

3

4

5

6

7

8

9

10

11

12

13

14

15

16

17

18

19

20

21

22

23

24

25

26

27

28

29

30

31

32

33

34

35

36

37

38

39

40

41

42

43

44

45

46

47

48

49

50

51

52

53

54

55

56

57

58

59

60 . . 4 . .

\begin{tabular}{llll} 
Filament & Angle outside $\left(^{\circ}\right)$ & Angle inside $\left(^{\circ}\right)$ & $\mu_{0}$ \\
\hline B1 cPLA1 & 2D random & 2D random & 0.375 \\
B2 cPLA1 & 2D random & 2D random & 0.375 \\
F1 cPLA1 & 2D random & 2D random & 0.375 \\
B3 cPLA1 & 6.31 & 19.90 & 0.821 \\
B3 cPLA2 & 4.50 & 29.71 & 0.653 \\
B 4 cPLA1 & 4.54 & 26.89 & 0.704 \\
B4 cPLA2 & 4.54 & 25.90 & 0.721
\end{tabular}

.

(n)

(n)

.
. . . 
Table 1 The theoretical modulus compared to the experimental modulus of the filaments and their improvements

\begin{tabular}{lllll} 
Filament & $E_{\text {exp }}(\mathrm{GPa})$ & $E_{\text {th }}(\mathrm{GPa})$ & $\frac{E_{\text {exp }}-E_{c P L A x}}{E_{c P L A x}}(\%)$ & $\frac{E_{\text {exp }}}{E_{\text {th }}}(\%)$ \\
\hline B1 cPLA1 & $1.55 \pm 0.26$ & 1.10 & 22.05 & 1.41 \\
B2 cPLA1 & $1.77 \pm 0.42$ & 1.07 & 39.37 & 1.65 \\
B3 cPLA1 & $2.43 \pm 0.42$ & 1.78 & 91.34 & 1.36 \\
B3 cPLA2 & $2.55 \pm 0.28$ & 1.04 & 214.81 & 2.46 \\
B4 cPLA1 & $2.76 \pm 0.44$ & 1.34 & 117.32 & 2.06 \\
B4 cPLA2 & $2.67 \pm 0.19$ & 1.17 & 229.63 & 2.29 \\
F1 cPLA1 & $2.42 \pm 0.30$ & 2.02 & 90.55 & 1.20 \\
F2 cPLA1 & $2.25 \pm 0.19$ & $/$ & 77.17 & $/$ \\
Reference & $2.43 \pm 0.11$ & $/$ & $/$ & $/$ \\
cPLA1 & $1.27 \pm 0.52$ & $/$ & $/$ & $/$ \\
cPLA2 & $0.81 \pm 0.07$ & $/$ & $/$ & $/$ \\
PLA & $4.27 \pm 1.27$ & $/$ & $/$ & $/$ \\
\hline
\end{tabular}


Table 1 The measured advancing, receding and equilibrium contact angles in combination with water (WT), ethylene glycol (EG) and Diiodomethane (DIO). The velocity of the measurements was $2.0 \mathrm{~mm} / \mathrm{min}$. Each measurement is the mean of 6 samples who are measured 3 times

\begin{tabular}{|c|c|c|c|c|c|c|}
\hline \multirow[b]{2}{*}{ Liquid } & \multicolumn{3}{|l|}{ cPLA1 } & \multicolumn{3}{|l|}{ cPLA2 } \\
\hline & $\mathrm{adv}$ & rec & equ & $\mathrm{adv}$ & rec & equ \\
\hline WT & $85.19 \pm 2.08$ & $52.06 \pm 1.35$ & $68.63 \pm 1.50$ & $77.27 \pm 2.14$ & $42.89 \pm 2.45$ & $60.08 \pm 1.36$ \\
\hline EG & $59.02 \pm 3.75$ & $13.33 \pm 4.11$ & $36.21 \pm 3.55$ & $57.80 \pm 2.76$ & $16.35 \pm 6.50$ & $37.08 \pm 4.29$ \\
\hline DIO & $51.77 \pm 3.72$ & $29.81 \pm 2.35$ & $41.79 \pm 2.77$ & $51.28 \pm 2.72$ & $30.06 \pm 2.52$ & $40.11 \pm 3.34$ \\
\hline
\end{tabular}


Table 1 The acid-base approach of the surface energy components of Bamboo fibers, flax fibers and 2 types of compounded PLA.

\begin{tabular}{|c|c|c|c|c|c|c|}
\hline Material & $\gamma\left(\frac{m J}{m^{2}}\right)$ & $\gamma^{L W}\left(\frac{m J}{m^{2}}\right)$ & $\gamma^{A B}\left(\frac{m J}{m^{2}}\right)$ & $\gamma^{+}\left(\frac{m J}{m^{2}}\right)$ & $\gamma^{-}\left(\frac{m J}{m^{2}}\right)$ & Refe \\
\hline Bamboo & $38.82 \pm 0.76$ & $35.44 \pm 0.06$ & $3.37 \pm 0.57$ & $0.28 \pm 0.06$ & $10.13 \pm 1.25$ & {$[25]$} \\
\hline Flax & 37.0 & 35.0 & 2.0 & 0.08 & 11.7 & [44] \\
\hline cPLA1 & $41.40 \pm 1.68$ & $38.70 \pm 0.23$ & $2.53 \pm 0.75$ & $0.48 \pm 0.32$ & $4.95 \pm 0.31$ & / \\
\hline cPLA2 & $41.78 \pm 1.89$ & $39.55 \pm 0.27$ & $2.61 \pm 1.04$ & $0.25 \pm 0.38$ & $8.80 \pm 0.30$ & l \\
\hline
\end{tabular}


1

2

3

4

5

6

7

8

9

10

11

12

13

14

15

16

17

18

19

20

21

22

23

24

25

26

27

28

29

30

31

32

33

34

35

36

37

38

39

40

41

42

43

44

45

46

47

48

49

50

51

52

53

54

55

56

57

58

59

60

Table 1 The wetting parameters between bamboo and flax with 2 types of compounded PLA.

\begin{tabular}{lcccc} 
Interface & $W_{a}\left(\frac{\mathrm{mJ}}{\mathrm{m}^{2}}\right)$ & $S\left(\frac{\mathrm{mJ}}{\mathrm{m}^{2}}\right)$ & $\gamma_{s l}\left(\frac{\mathrm{mJ}}{\mathrm{m}^{2}}\right)$ & $\Delta F\left(\frac{\mathrm{mJ}}{\mathrm{m}^{2}}\right)$ \\
\hline Bamboo/cPLA1 & $80.84 \pm 2.31$ & $-2.72 \pm 2.31$ & $-0.24 \pm 1.91$ & $39.06 \pm 2.06$ \\
Flax/cPLA1 & $79.67 \pm 2.19$ & $-3.90 \pm 2.19$ & $-0.89 \pm 1.91$ & $37.89 \pm 1.91$ \\
Bamboo/cPLA2 & $81.21 \pm 4.27$ & $-3.82 \pm 4.27$ & $0.13 \pm 3.54$ & $38.69 \pm 3.62$ \\
Flax/cPLA2 & $79.57 \pm 4.27$ & $-5.46 \pm 4.27$ & $-0.06 \pm 3.62$ & $37.06 \pm 3.62$ \\
\hline
\end{tabular}

John Wiley \& Sons 
Table 1 The glass transition temperatures of the produced and reference filaments

\begin{tabular}{ll} 
Filament & $T_{g}\left({ }^{\circ} \mathrm{C}\right)$ \\
\hline B1 cPLA1 & 39.8 \\
B2 cPLA1 & 39.2 \\
B3 cPLA1 & 41.9 \\
B3 cPLA2 & 27.1 \\
B4 cPLA1 & 37.6 \\
B4 cPLA2 & 27.6 \\
F1 cPLA1 & 38.3 \\
cPLA1 & 40.1 \\
cPLA2 & 28.8 \\
PLA & 61.6 \\
Reference & 59.2 \\
\hline
\end{tabular}

16

17

18

19

20

21

22

23

24

25

26

27

28

29

30

31

32

33

34

35

36

37

38

39

40

41

42

43

44

45

46

47

48

49

50

51

52

53

54

55

56

57

58

59

60

John Wiley \& Sons 
Figure 1 Screw profile and temperature settings of the Leistritz ZSE 18 MAXX 36D compounder, with 36 segments of length equal to the screw diameter $D$

$123 \times 53 \mathrm{~mm}(300 \times 300 \mathrm{DPI})$

John Wiley \& Sons 


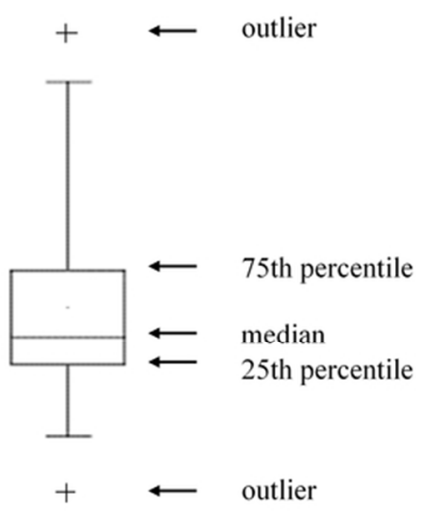

Figure 2 Illustration of the boxplots $72 \times 32 \mathrm{~mm}(300 \times 300 \mathrm{DPI})$

John Wiley \& Sons 
Before compounding

Figure 3 Boxplot of the fiber length and diameter distribution of the different fiber fractions before compounding, measured by an automated image processing algorithm

$87 \times 43 \mathrm{~mm}(300 \times 300$ DPI $)$ 
Figure 4 Boxplot of the fiber length and diameter distribution of the fiber fractions B3, B4 and F1 after compounding, measured by an image processing algorithm. Fractions B1, B2 and F2 were not measured due to difficulties during dissolving, related with to the particle dimensions

\section{$90 \times 47 \mathrm{~mm}(300 \times 300$ DPI $)$}




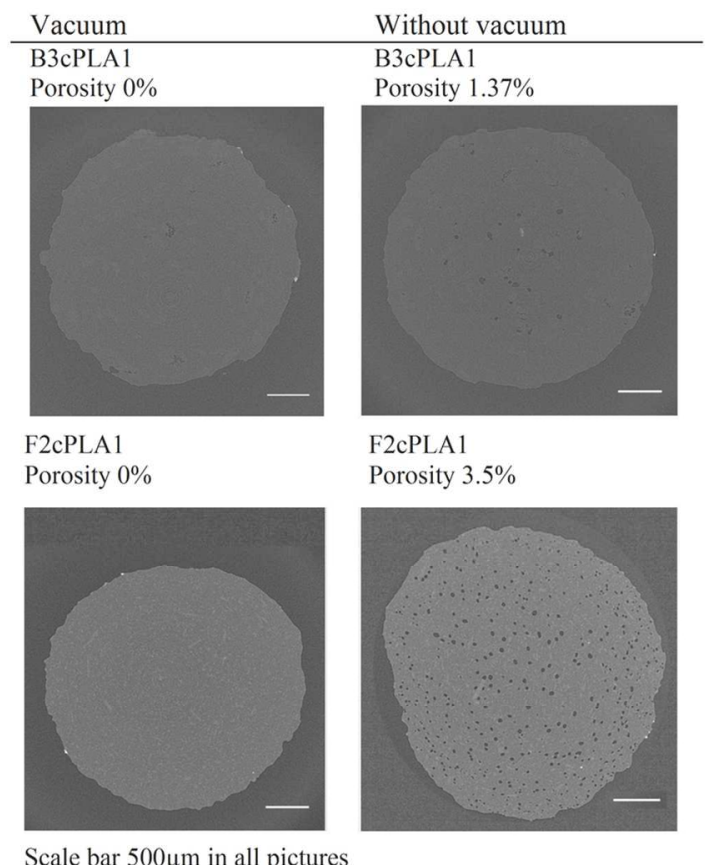

Scale bar $500 \mu \mathrm{m}$ in all pictures

Figure 5 Influence of vacuum on the filament porosity $119 \times 89 \mathrm{~mm}(300 \times 300$ DPI $)$ 


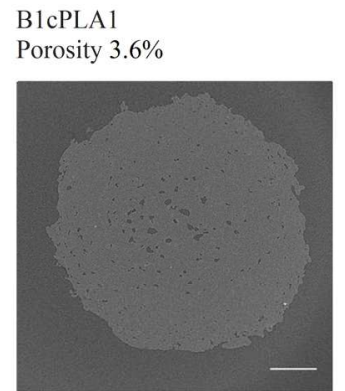

B3cPLA2

Porosity $4.2 \%$

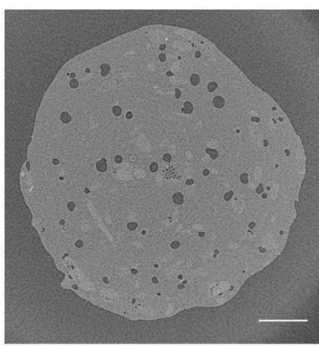

F IcPLAI

Porosity $0 \%$

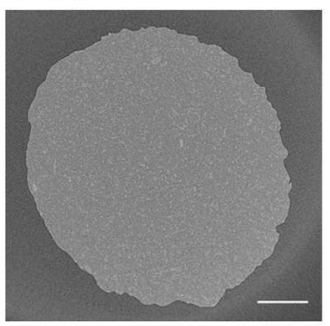

Scale bar $500 \mu \mathrm{m}$
B2cPLA1

Porosity $3.6 \%$

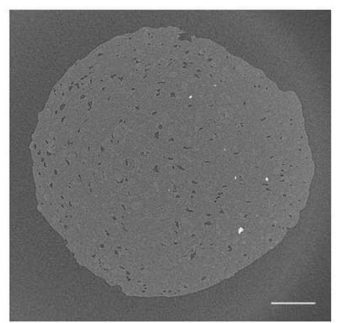

B1cPLA1

Porosity $8.9 \%$

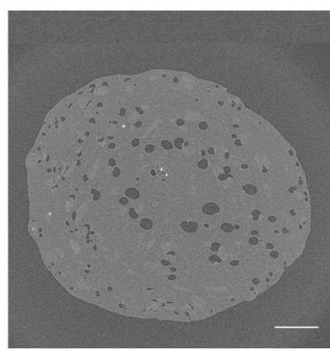

F2cPLAI

Porosity $0 \%$

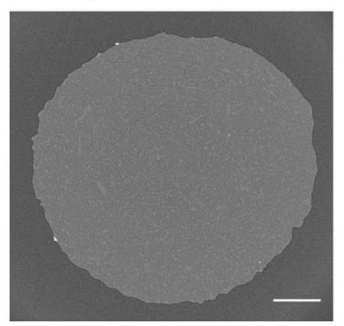

B3cPLA1

Porosity $0.3 \%$

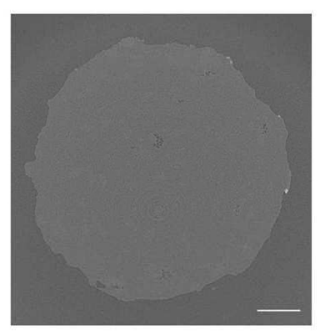

B1cPLA2

Porosity $4.4 \%$

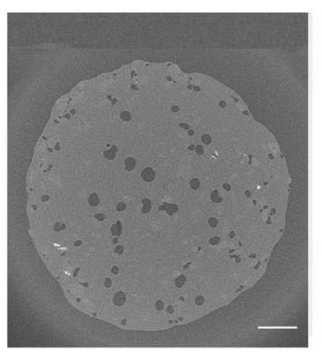

Reference

Porosity $13 \%$

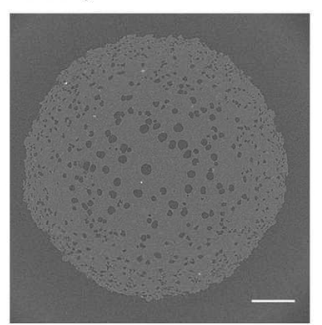

Figure 6 Porosities of the different produced filaments. The dark grey areas are air, the light grey areas are fibers and the grey area is the matrix

$170 \times 182 \mathrm{~mm}(300 \times 300$ DPI $)$ 
a)

b)
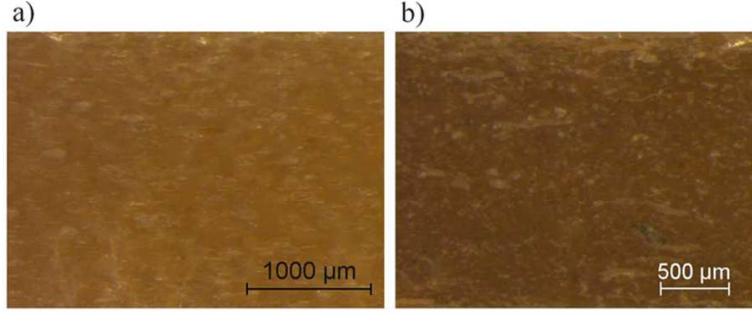

c)

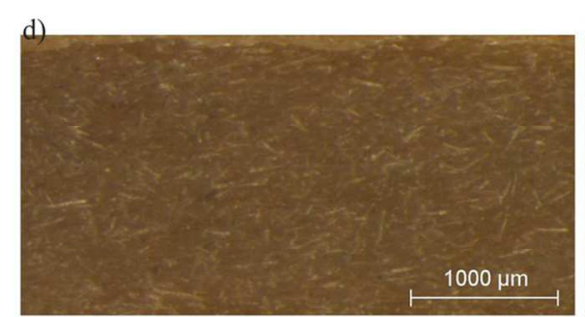

e)
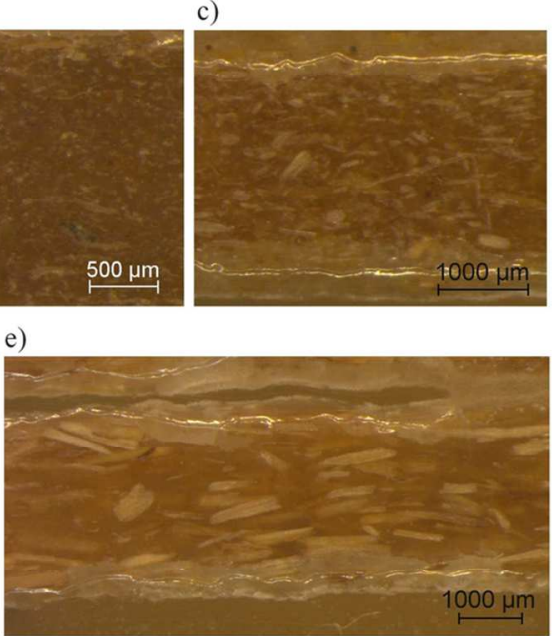

Figure 7 Microscopic pictures of a longitudinal cross section of (a) the Reference filament, (b) the B1cPLA1 filament, (c) the B2cPLA1 filament and (d) the F1cPLA1 filament and (e) the B3cPLA1 filament. The Reference, $\mathrm{F} 1, \mathrm{~B} 1$ and $\mathrm{B} 2$ fibers show random orientation

$$
105 \times 70 \mathrm{~mm}(300 \times 300 \mathrm{DPI})
$$



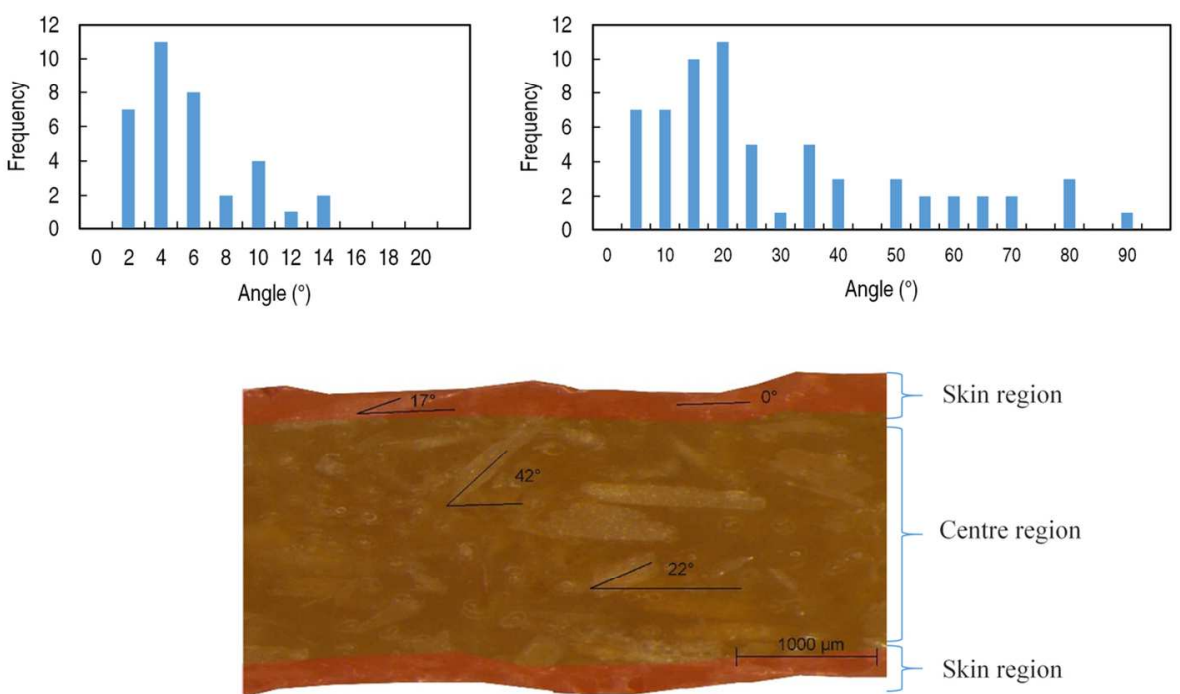

Figure 8 Microscopic picture of the B4CPLA2 filament, with indication of the center and skin region as well as some indicated fiber angle measurements and the two according histograms

$120 \times 91 \mathrm{~mm}(300 \times 300$ DPI $)$ 

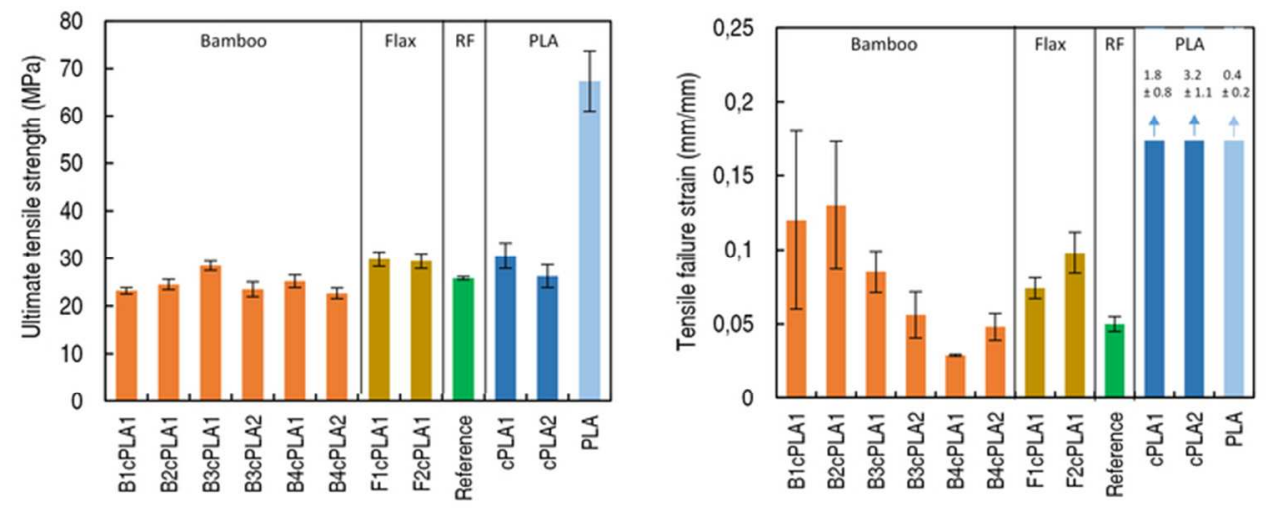

Figure 9 Results of the tensile tests for the ultimate tensile strength and failure strain of the different filaments considered

$67 \times 28 \mathrm{~mm}(300 \times 300 \mathrm{DPI})$ 
a)

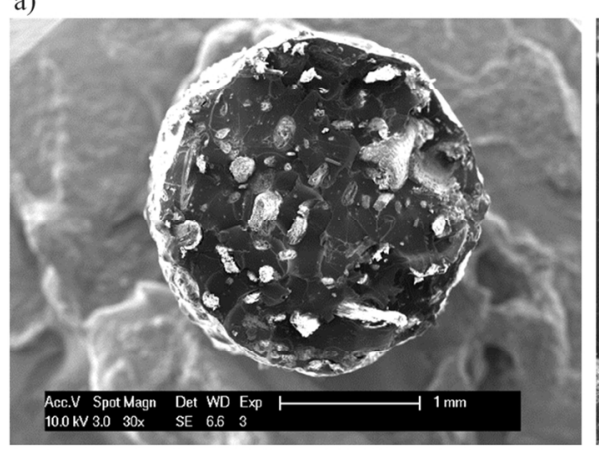

c)

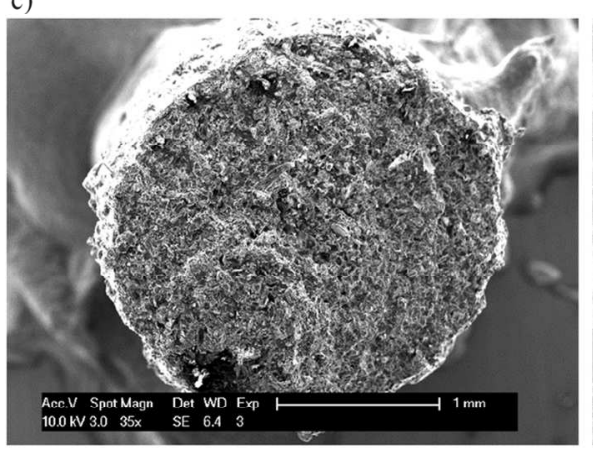

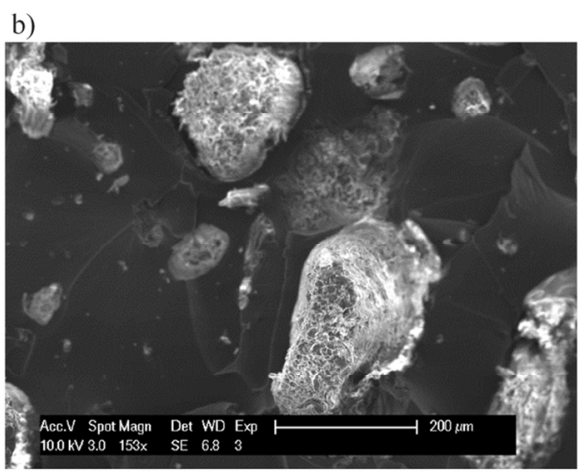

d)

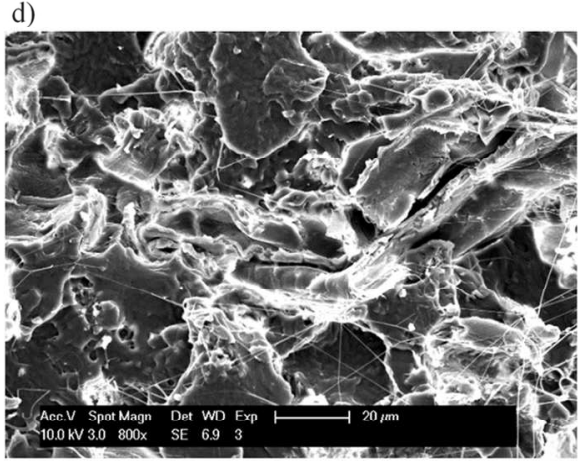

Figure 10 The scanning electron microscope pictures of (a) the B3cPLA1 filament, (b) a close-up of B3cPLA1 filament, (c) B1cPLA1 filament and (d) a close up of the B1cPLA1 filament

$128 \times 103 \mathrm{~mm}(300 \times 300 \mathrm{DPI})$ 
a)

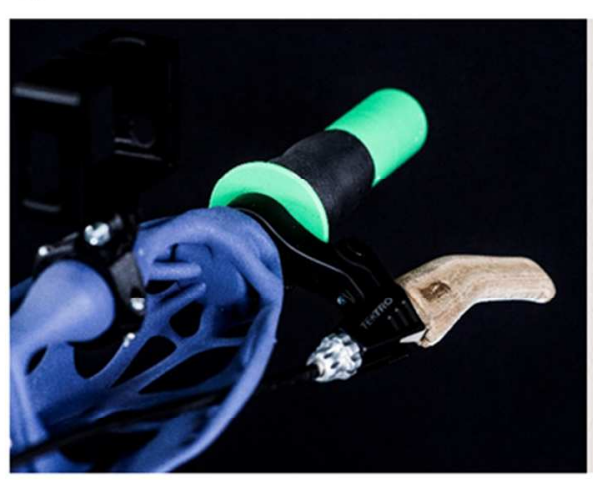

b)

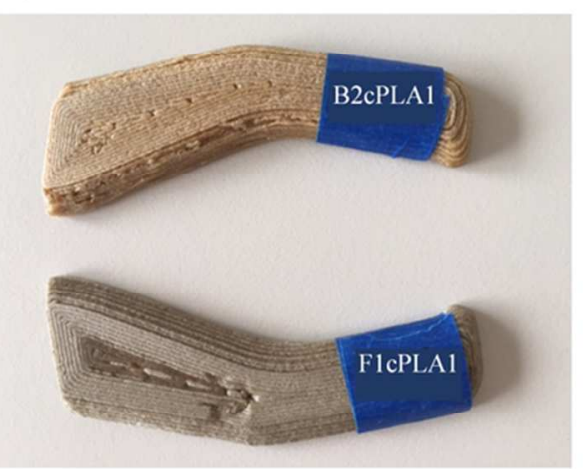

Figure 11 (a) Demonstrator brake lever printed out of B2cPLA mounted on the王-BIKE (Photographer: Filip Van Loock, 2016), (b) Brake lever part printed out of B2cPLA1 and F1cPLA1

$$
72 \times 33 \mathrm{~mm}(300 \times 300 \mathrm{DPI})
$$

